\title{
УЛЬТРАЗВУКОВЫЕ ТЕХНОЛОГИИ В ДИАГНОСТИКЕ И ЛЕЧЕНИИ БОЛЬНЫХ С ПАНКРЕОНЕКРОЗАМИ
}

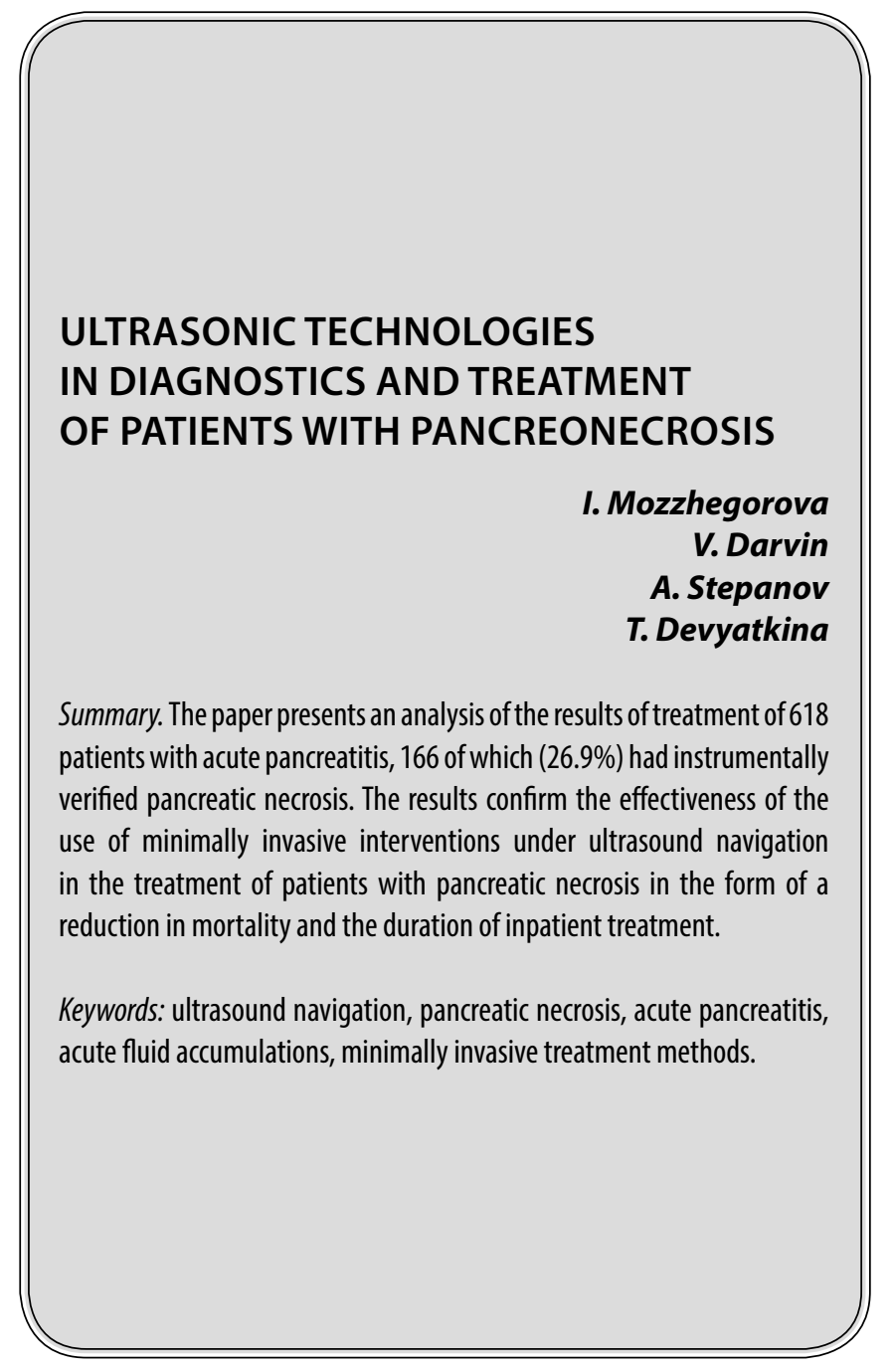

\section{Введение}

$\mathbf{H}$ еуклонный рост количества больных с острой хирургической патологией органов брюшной полости и забрюшинного пространства, протекающих с деструктивным процессом, оставляет актуальным вопрос оптимальной тактики и выбора конкретного хирургического метода лечения больных с данной патологией в абдоминальной хирургии $[1,2,3]$. Ведущая роль в неотложной абдоминальной хирургии принадлежит острому панкреатиту, который занимает второе место в структуре острых хирургических заболеваний $[4,5]$. Наиболее грозной формой острого панкреатита является распространенный панкреонекроз с развитием перитонита, забрюшинной флегмоны и формированием
Мозжегорова Изабель Викторовна Аспирант, Сургутский государственный университет; врач ультразвуковой диагностики, Сургутская окружная клиническая больнича mozzhegorovaiv@surgutokb.ru

Дарвин Владимир Васильевич Д.м.н., профессор, Сургутский государственный университет darvinvv@surgutokb.ru Степанов Александр Викторович

Хирург, Сургутская окружная клиническая больнича stepanovav@surgutokb.ru

Девяткина Татьяна Валерьевна

Заведующая отделением ультразвуковой диагностики, Сургутская окружная клиническая

больница

devyatkinatv@surgutokb.ru

Аннотация. В работе представлен анализ результатов лечения 618 больных с острым панкреатитом, у 166 из которых (26,9\%) имел место инструментально верифицированный панкреонекроз. Полученные результаты подтверждают эффективность использования малоинвазивных вмешательств под ультразвуковой навигацией в лечении больных с панкреонекрозом в виде снижения летальности и длительности стационарного лечения.

Ключевые слова: ультразвуковая навигация, панкреонекроз, острый панкреатит, острые жидкостные скопления, малоинвазивные методы лечения.

острых жидкостных скоплений различной локализации. Общая летальность при остром панкреатите варьируется в пределах 3-6\%, при этом основная доля летальных исходов приходится на инфекционные осложнения $40-80 \%[6,7]$. Хотя в последние годы наметилась некоторая тенденция к снижению общей летальности (с 4,0\%4,5\% до 2,5\%-3,5\%), однако при этом послеоперационная летальность сохраняется на довольно высоком уровне (20\%-25\%) [8-12]. В связи с этим определение роли и места малоинвазивных вмешательств при диагностике и хирургическом лечении больных с панкреонекрозом является важной и актуальной проблемой, при этом ультразвуковые технологии из-за с отсутствия лучевой нагрузки, возможности динамического наблюдения за ходом лечебного процесса, на сегодняшний день наи- 
Таблица 1. Распределение пациентов по полу и возрасту

\begin{tabular}{|l|l|l|l|l|}
\hline Возрастные группы (лет) & Мужчин (человек) & Доля (\%) & Женщин (человек) & Доля (\%) \\
\hline $21-40$ & 126 & 20,5 & 38 & 6,2 \\
\hline $41-60$ & 137 & 22,3 & 101 & 16,5 \\
\hline 61 и старше & 81 & 13,1 & 132 & 21,5 \\
\hline Всего & 344 & 55,8 & 274 & 44,3 \\
\hline
\end{tabular}

более перспективны для оптимизации малоинвазивных технологий. В операционных и рентгенологических кабинетах возможно проведение диагностических и малоинвазивных вмешательств благодаря наличию портативных УЗ-сканеров с высокой разрешающей способностью и идущих к ним интраоперационных датчиков.

\section{Цель исслеАования}

Определить эффективность применения малоинвазивных методик диагностики и лечения под контролем ультразвукового исследования у больных с острым панкреатитом средней и тяжелой степени.

\section{Материалы и метомы}

Проведен анализ результатов лечения 618 больных с верифицированным диагнозом «Острый панкреатит», госпитализированных и пролеченных в БУ «Сургутская окружная клиническая больница» в течение 20152019 г.г. В таблице 1 представлено распределение больных по полу и возрасту.

То есть, преобладали лица мужского пола - 55,8\%. При этом среди мужчин большая доля (22,3\%) приходится на возраст 41-60 лет, а среди женщин (21,5\%)на возраст старше 60 лет. Средний возраст составил 53,2 $\pm 3,5$ года.

Диагноз и степень тяжести заболевания при поступлении (или при переводе из других ЛПУ) установлен на основании клинических, лабораторных данных и данных УзИ. Ультразвуковая диагностика проводилась на сканере высокого класса Affiniti 30 Philips, Италия с использованием конвексного датчика 3,5-5,5 МГц. Кроме того, для верификации степени тяжести заболевания и оценки морфологического субстрата, у 193 (38,8\%) больных в течение первых трех суток от момента поступления проведена компьютерная томография (КТ). Компьютерная диагностика проводилась на рентгеновском компьютерном томографе производства «Toshiba Medical Systems Corporation», Япония.

В соответствии с критериями оценки тяжести заболевания (Клинические рекомендации «Острый панкреатит, 2019 г) острый панкреатит легкой степени установлен у 452 пациентов (73,1\%), острый панкреатит средней степени - у 98 пациентов (15,9\%), острый панкреатит тяжёлой степени - у 68 больных $(11,0 \%)$.

Консервативная терапия больным с острым панкреатитом проводилась соответственно положениям национальных клинических рекомендаций, объём определялся фазой и тяжестью заболевания.

В группе больных с острым панкреатитом средней и тяжёлой степени хирургические методы лечения применены у 101 больного (60,8\%), из которых у 76 больных основной хирургической технологией были малоинвазивные вмешательства под УЗ наведением, а у 25 - прочие хирургические вмешательства (путем лапаротомии или широкой люмботомии или их сочетания), 65 больных (39,2\%) пролечены без использования инвазивных хирургических методик.

Миниинвазивные вмешательства под ультразвуковой навигацией (УЗН) проводились с использованием ультразвукового аппарата экспертного класса «MyLabTwices» Esaote, Италия. При необходимости интраоперационного исследования использовался портативный ультразвуковой аппарат «Logiq e» с конвексным датчиком 3,5 МГц.

Малоинвазивные хирургическими вмешательствами (основания группа исследования) выполнены у 76 больных с острым панкреатитом (12,3\% от всех больных с острым панкреатитом), из них средней степени тяжести - у 42 (42,8\%) и тяжелой степени - у 34 (50,0\%).

Таким образом, хирургическая активность при расчете на всю группу больных с острым панкреатитом, составила $16,3 \%$, а у больных с острым панкреатитом средней и тяжёлой степени - 60,8\%.

В ранней (I В) фазе стерильного панкреонекроза инвазивные вмешательства выполнены у 9 больных - 8,9\% (из них у 6 - при средней тяжести и у 3 - при тяжёлом течении). В поздней фазе (II) асептического и инфицированного панкреонекроза инвазивные вмешательства выполнены у 92 больных - 91,1\% (из них 36 - средней тяжести и 31 - тяжёлое течение). 
Показаниями к применению хирургических методов лечения у больных с верифицированным панкреатитом средней и тяжёлой степени являлись:

- острые жидкостные скопления (36 пациентов $35,5 \%)$

- асептический некроз с резвившейся полиорганной недостаточностью, не отвечающий на проводимую консервативную терапию (9-8,9\%);

- отграниченная септическая секвестрация панкреонекроза с формированием абсцессов (24-23,8\%);

- распространенная септическая секвестрация с формированием парапанкреатических флегмон и флегмон забрюшинного пространства (2221,8\%);

- гнойный перитонит (2-2,0\%);

- деструктивный холецистит (4-4,0\%);

- иные осложнения: кровотечения, некроз и перфорация толстой кишки, внутренние кишечные свищи (4-4,0\%).

Примененные малоинвазивные хирургические технологии по УзН, выполненные в ранней фазе (I В) стерильного панкреонекроза:

- дренирование острых жидкостных скоплений объёмом от 200 мл и более по методике Сельдингера, с установкой одного и более дренажей 12-18 Fr по шкале Chauiere, типа pig-tail - у 6 больных.

В поздней фазе заболевания (II) выполняли:

- дренирование нагноившихся жидкостных скоплений, абсцессов, кист под УзН - у 38 больных $(54,2 \%)$;

- минидоступы с длиной разреза до 4 см и установкой дренажей более крупного диаметра (до 30-33 Fr) использовали при отсутствии акустического окна, наличия петель кишечника на пути к зоне дренирования под УЗН или при недостаточной эффективности пункционного дренирования у 10 больных (14,3\%);

- минидоступы под УЗН при распространенном гнойно-деструктивном процессе в виде инфицированного парапанкреатита, забрюшинных флегмон, распространенном оментобурсите - 22 $(31,4 \%)$.

При локализации гнойно-деструктивного процесса в области головки поджелудочной железы и распространённом гнойном оментобурсите использовали минилапаротомию по средней линии в эпигастральной области. При гнойно-деструктивном процессе в забрюшинной клетчатке применяли мини-доступы в поясничных и подвздошных областях справа или слева в зависимости от локализации.
У 25 больных (24,8\%) хирургические вмешательства выполнены путём традиционной лапаротомии, широкой люмботомии или их сочетание. Основным показанием были: распространенная септическая секвестрация с формированием забрюшинных флегмон, распространенный гнойный перитонит и иные осложнения тотального панкреонекроза (кровотечения, некроз и перфорация толстой кишки, внутренние кишечные свищи).

\section{Результаты}

Средняя длительность стационарного лечения у больных с острым панкреатитом составила 13,9+4,0 койко-дней; при легком течении - 8,8 + 2,3; при средней тяжести - 15,7+4,6; при тяжелом - 25,5 + 6,5 койко-дня.

Общая летальность у пациентов с верифицированным острым панкреатитом составила 2,75\%. (17 человек.). Причинами летальных исходов явились: сепсис, СПОН - у 11, острый инфаркт миокарда - у 1, кровотечение с тяжёлой анемией, ДВС-синдром и СПОН - у 2, острое нарушение мезентериального кровообращения - у 2, фульминантное течение острого панкреатита - 1. При остром панкреатите легкой степени летальных исходов не было.

При остром панкреатите средней тяжести и тяжёлом остром панкреатите летальность составила 10,2\%. При этом в группе больных с острым панкреатитом средней и тяжёлой степени, у которых применены малонвазивные методы лечения с УЗН, в послеоперационном периоде умерло 7 больных, послеоперационная летальность составила 9,2\%, при применении традиционной лапаротомии и широкой люмботомии в послеоперационном периоде умерли 8 больных, послеоперационная летальность $32,0 \%(p<0,01)$.

\section{Выво $ы$}

1. Доля больных с панкреонекрозом от общего количества больных с острым панкреатитом составляет 26,9\%, при этом у 15,9\% больных острый панкреатит имеет течение средней тяжести и у $11,0 \%$ - тяжелое течение.

2. Показания и возможности для выполнения малоинвазивных хирургических вмешательств под УзН у больных с панкреонекрозом имеют место у 8,2\% - в ранней фазе и у 85,5\% больных в поздней.

3. Использование УЗ технологий при выполнении малоинвазивных хирургических вмешательств у больных с острым панкреатитом средней и тяжелой степени позволяет снизить послеоперационную летальность с 14,9\% до 9,2\% 


\section{ЛИТЕРАТУРА}

1. Гальперин Э.И., Дюжева Т. Г., Докучаев К. В. и др. Инфицированный панкреонекроз. Хирургия. 2002; 9: 82-84.

2. Нестеренко Ю.А., Михайлусов С. В., Черняков А. В. Лечение больных сострыми жидкостными образованиями поджелудочной железы и сальниковой сумки. Анналы хирургической гепатологии. 2006; 3: 23-28.

3. Савельев В.С., Филимонов М. И., Гельфанд Б. Р. и др. Панкреонекроз: актуальные вопросы классификации, диагностики и лечения. Соnsilium-medicum. 2000; 7:34-39.

4. Новые подходы к фармакотерапии острого панкреатита /Ю.В.Иванов [и др.]// Хирургия.— 2005.— № 2. URL http: www.medinfa.ru.

5. Эндовидеохирургические вмешательства в лечении гнойно-некротических осложнений панкреонекроза: материалы международного конгресса хирургов /М.А.Сидоров [и др.]. - Петрозаводск, 2002. - С. 199-201.

6. Connor S., Raraty M.G, Lowes N. I. Surgery in the treatment of acutepancreatitis-minimal access pancreatic necrosectomy. Scand J Surg. 2005; 94:2:135-42.

7. Otsuki M., Noshimori l., Hauakawa T. et al. Hereditary pancreatitis: clinical characteristics and diagnostic criteria in Japan. Pancreas 2004; 28: 2: 200-206.

8. Ермолов А.С., Иванов П. А., Благовестнов Д. А. Диагностика и лечение острого панкреатита. М.: ВИДАР, 2013. 382с.

9. Дарвин В.В., Онищенко С. В., Логинов Е. В., Кабанов А. А. Тяжелый острый панкреатит: факторы риска неблагоприятного исхода и возможности их устранения // Анналы хирургической гепатологии. 2018., т. 23. № 2. С. 76-83.

10. Национальное руководство по хирургии. / под ред. Савельева В.С., Филимонова М. И., Бурневич С. 3., том 2 изд. 2013: ГЭОТАР-Медиа. 2013.832 С.

11. Кубышкин, В. А. Острый панкреатит // Тихоокеанский медицинский журнал. 2009. № 2. С. 48-52.

12. IAP/APA evidence-based guidelines for the management of acute pancreatitis. Working Group IAP/APA (International Association of Pancreatology /American Pancreatic Association) Acute Pancreatitis Guidelines // Pancreatology. 2013. № 13. C. E1-e16

( ) Мозжегорова Изабель Викторовна ( mozzhegorovaiv@surgutokb.ru ), Дарвин Владимир Васильевич ( darvinvv@surgutokb.ru ),

Степанов Александр Викторович ( stepanovav@surgutokb.ru), Девяткина Татьяна Валерьевна ( devyatkinatv@surgutokb.ru).

Журнал «Современная наука: актуальные проблемы теории и практики»

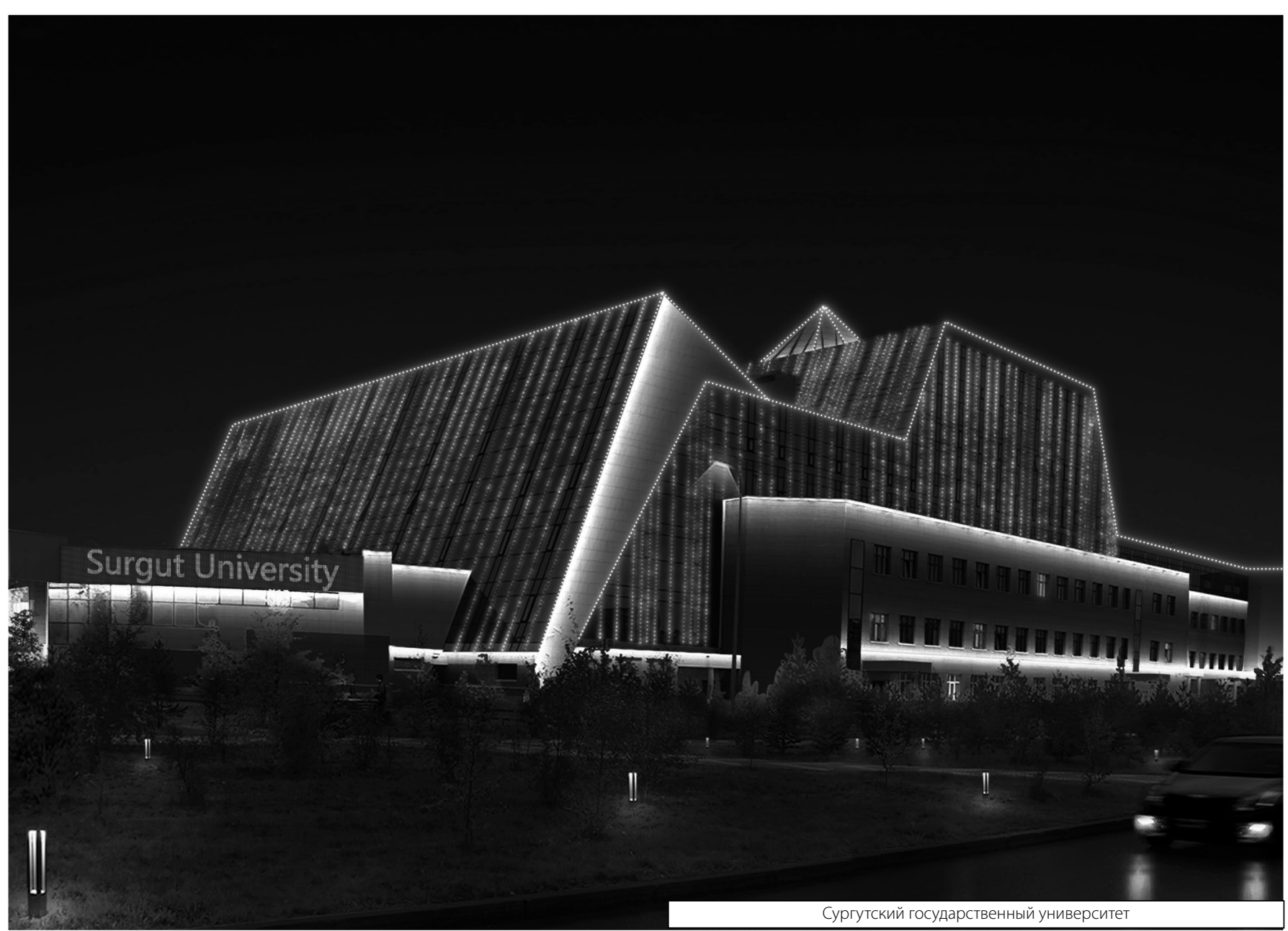

